\title{
O ESTADO DA ARTE DO ENSINO DE GEOGRAFIA DO BRASIL A PARTIR DO USO DE NOVAS TECNOLOGIAS
}

\author{
Wilcilene da Silva Corrêa \\ Mestranda pelo Programa de Pós-graduação em Geografia - UFAM \\ Universidade Federal do Amazonas \\ prof.wilcilenecorrea@hotmail.com \\ Amélia Regina Batista Nogueira \\ Professora Doutora do Programa de Pós-graduação em Geografia - UFAM \\ Universidade Federal do Amazonas \\ ab.nogueira@uol.com.br
}

RESUMO: A proposta da pesquisa tem como principal objetivo buscar uma compreensão mais ampla acerca do desenho que traçam as metodologias do ensino de geografia no Brasil, a partir da análise de uma década de contribuições das pesquisas sobre o ensino de geografia em nível strictu sensu (mestrado e doutorado) que compõe o banco de dados da CAPES. Deste modo, verificar-se-á o estado da arte do ensino de Geografia, buscando compreender como se apresentam as metodologias de ensino na Geografia nos últimos dez anos e especialmente, de que forma o uso de novas tecnologias tem contribuído como ferramenta facilitadora da aprendizagem na geografia.

Palavras-chave: Ensino de geografia, estado da arte, tecnologia no ensino.

\section{INTRODUÇÃO}

O ensino de geografia é um tema desafiador, pois ao mesmo tempo em que se faz presente desde a educação básica e é uma ciência de nível superior, a forma de ensinar geografia ainda é pouco refletida e discutida, diante de tantas questões e desafios apresentados na realidade dos professores, especialmente nos níveis fundamental e médio.

Quando essa discussão acontece, por vezes ela se dá em âmbito distanciado de onde mais poderia influenciar a educação, ou seja, a escola, junto aos professores, que se veem diante do bombardeio de informações fragmentadas a título de conteúdo a que seu alunado está sujeito.

Deste modo, reflete-se sobre a forma como o ensino de geografia tem contribuído para a formação dos mais diversos profissionais que atuam sobre o espaço geográfico e a importância de elevar a qualidade do ensino por meio de uma relação mais sólida entre o universo da pesquisa e o da sala de aula.

Deste modo, os estudos acerca do ensino de geografia de modo geral têm se mostrado bastante diversificados, o que acaba conferindo uma importante contribuição para o panorama do contexto de ensino e aprendizagem desta ciência.

Tendo este trabalho como objetivo primordial compreender como se apresentam as metodologias de ensino na Geografia nos últimos dez anos e de que forma o uso de 
novas tecnologias tem contribuído como ferramenta de aprendizagem, abordaremos a produção científica e as metodologias de ensino apresentadas por autores voltados para o ensino de geografia, bem como a busca da produção científica da última década em ambiente virtual (catálogo de teses e dissertações da Capes) buscando entender as correntes teórico-metodológicas mais presentes no ensino de geografia no Brasil propondo a discussão dessas metodologias, bem como a identificação do uso de metodologias voltadas para a evolução tecnológica na tentativa de compreender até que ponto as mesmas tem sido facilitadoras da aprendizagem no ensino de geografia.

\title{
MATERIAIS E MÉTODOS
}

Para o desenvolvimento da pesquisa, levamos em conta inicialmente a metodologia definida como "estado da arte" ou "estado do conhecimento", que de acordo com Ferreira (2002) tem se apresentado nos últimos quinze anos no Brasil e em outros países. De acordo com a autora, essas pesquisas:

\begin{abstract}
Definidas como de caráter bibliográfico, elas parecem trazer em comum o desafio de mapear e de discutir uma certa produção acadêmica em diferentes campos do conhecimento, tentando responder que aspectos e dimensões vêm sendo destacados e privilegiados em diferentes épocas e lugares, de que formas e em que condições têm sido produzidas certas dissertações de mestrado, teses de doutorado, publicações em periódicos e comunicações em anais de congressos e de seminários (FERREIRA, 2002, p. 257).
\end{abstract}

Possui caráter teórico e metodológico, onde partiremos da pesquisa qualitativa acerca do que vem sendo privilegiado na produção voltada para o ensino de geografia no Brasil ao longo da última década.

Seu caráter bibliográfico é definido por Marconi e Lakatos (2010, p. 166) como fonte secundária, que torna público todo o material já produzido, que passa a ser reforço ao pesquisador em sua análise. Ressalta ainda que esse tipo de pesquisa "não é mera repetição do que já foi dito ou escrito, (...) mas propicia o exame de um tema sob novo enfoque ou abordagem, chegando a conclusões inovadoras".

Por fim, nos utilizaremos de entrevistas com professores que atuam no ensino médio da educação básica, na tentativa de compreender como a tecnologia tem facilitado os processos de ensino e aprendizagem, o que se fará por meio de entrevista padronizada ou estruturada, com formulário previamente estabelecido (MARCONI; LAKATOS, 2010, p.181). 


\section{REVISÃO DE LITERATURA}

O campo de saber geográfico, de maneira não sistematizada, é inerente à própria existência humana, haja vista que a análise se pauta nas relações entre o homem e o espaço por ele ocupado, vivido e transformado ao longo da sua história.

A geografia vivenciou ao longo de sua formação e sistematização, a composição de um saber bastante variado, e ao longo do tempo, foi criando objetividade quanto ao método de pensar científico (REGO et al, 2007).

Gomes (2000) nos lembra que a relação homem-natureza era um tema geral de debate filosófico ainda no século XVIII, mesmo de modo geral e com problemáticas diversas. Aponta ainda para o século XVIII como momento de desenvolvimento da geografia propriamente dita. Para Santos (1988), a criação da geografia, de forma simplista, pode ser considerada a partir da crise que antecedeu o imperialismo ao final do século XIX.

Moreira (2014, p. 13), destaca sobre o surgimento da Geografia que, "no formato de base como a conhecemos, nasce das mãos de Kant", que observa os eventos do século XVIII como as revoluções Burguesa e Industrial, ocorrendo na Inglaterra e na França, e percebe que a Alemanha fica de fora de tais acontecimentos. O filósofo prussiano busca então a interação entre a natureza e o homem, pois pensá-los separadamente o incomodava. Busca na geografia, os conhecimentos da natureza e na História os conhecimentos humanos.

Partindo desse princípio para o contexto da geografia ensinada nas escolas, destacase Lacoste (1988) quando define a geografia como uma disciplina escolar e universitária simplória e maçante, descritiva onde se valoriza muito mais os aspectos físicos do mundo às custas de seu 'desinteresse' cultural em geral.Tal disciplina já foi muito questionada quanto à sua utilidade prática no ensino escolar e enquanto isso, nas universidades, a distância entre o saber produzido e as dificuldades dos professores de nível fundamental e médio são ignoradas (LACOSTE, 1988).

Com essa visão propagada por muitos anos de uma geografia marcada pela simplicidade e até mesmo inutilidade, se mistificou a função dessa ciência; um saber estratégico, militar, político, uma geografia para fazer a guerra, como afirma Lacoste.

Castellar e Vilhena (2011, p. 1) destacam que existem espaços ou pausas entre as mudanças ocorridas na geografia escolar, de tempos em tempos. Tais pausas caracterizam não apenas essas mudanças como também a relação dos alunos com o conhecimento geográfico, o que afirmam ser a "contradição entre a geografia das universidades e a das escolas básicas". Essa distância temporal desfavorece o ensino escolar da geografia, bem como alguns conteúdos são desfavorecidos pela escolha aleatória.

As autoras destacam a importância de uma educação geográfica em detrimento de muitos anos de ensino de geografia. Segundo elas:

A educação geográfica contribui para que os alunos reconheçam a ação social e cultural de diferentes lugares, as interações entre as sociedades e a 
dinâmica da natureza que ocorrem em diferentes momentos históricos (CASTELLAR; VILHENA, 2011, p. 8).

As autoras definem como "velho modo" a metodologia descritiva presente na geografia escolar, que se apresenta descontextualizada e sem significado para o aluno, dotado de senso comum. Seria a partir de uma educação geográfica que o aluno passaria a um raciocinar geograficamente, percebendo um rigor científico na leitura da realidade por meio da ciência geográfica.

Castrogiovanni (1999) destaca acerca da necessidade de conexão entre o percebido e o vivido, o conceitual e o teórico. Nos lembra ainda que no período globalizado em que vivemos, as tecnologias modernas assim como os meios de comunicação, tendem a exercer orientação e condução da vida e do comportamento social, se fazendo presentes e importantes em diversos aspectos.

Nesta realidade, o ensino de geografia passa a sofrer alterações por conta da existência de diversos mundos, e a globalização da economia e tecnologia seriam intocáveis e por isso mesmo, sem a necessidade de reflexão. E colabora:

\begin{abstract}
O processo de aprendizagem deve possibilitar que o aluno construa não apenas conceitos e categorias já elaboradas socialmente, mas que (re)signifique tais instrumentais a partir da compreensão do particular, do poder ser diferente nas interpretações e mesmo assim fazer parte do contexto (CASTROGIOVANNI, 1999, p. 83).
\end{abstract}

\title{
CONCLUSÕES
}

A pesquisa ainda encontra-se em andamento, mas a partir do que já foi pesquisado é possível entender que o ensino de geografia é uma área muitas vezes subjugada, mas que possui enorme importância para o contexto da formação cidadã e do conhecimento geográfico.

Existem muitos estudos voltados para a temática ensino de geografia e novas tecnologias, no entanto se faz necessário interligar de modo prático esse conhecimento produzido com quem realmente importa: educadores e alunos dos níveis de ensino médio, trazendo assim a perspectiva de metodologias mais contextualizadas com a realidade e que favoreçam uma educação geográfica.

\section{REFERÊNCIAS}

CASTELLAR, S; VILHENA, J. Ensino de Geografia. São Paulo: Cengage Learning, 2011. Col. Ideias em Ação.

CASTROGIOVANNI, A. C. E agora, como fica o ensino da geografia com a globalização? In: CASTROGIOVANNI, A. C. et al. Geografia em sala de aula: práticas e reflexões. $2^{a}$ ed. UFGRS/AGB. Porto Alegre, 1999. 
O ESTADO DA ARTE DO ENSINO DE GEOGRAFIA DO BRASIL A PARTIR DO USO DE NOVAS TECNOLOGIAS

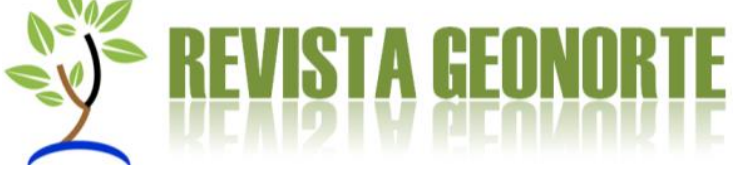

GOMES, P. C. C. Geografia e Modernidade. $2^{\underline{a}}$ ed. Rio de Janeiro: Bertrand Brasil, 2000.

KANT, I. Da estética transcendental do espaço. In: Crítica da Razão Pura. Lisboa: Edição da Fundação Calouste, 2001.

LACOSTE, Y. A geografia - isso serve em primeiro lugar, para fazer a guerra. $12^{\mathrm{a}}$ ed. Campinas-SP: Papirus, 2006.

MARCONI, M.A; LAKATOS, E. M. Fundamentos de Metodologia Científica. 7ª ed. São Paulo: Atlas, 2010.

MOREIRA, R. Para onde vai o pensamento geográfico? Por uma epistemologia crítica. 2 ed. São Paulo: Contexto, 2014. 